\title{
European integration, productivity growth and real convergence
}

\author{
Ali M. Kutan ${ }^{\mathrm{a}, \mathrm{b}, \mathrm{c}, \mathrm{d}}$, Taner M. Yigit ${ }^{\mathrm{e}, *}$ \\ ${ }^{a}$ Economics and Finance Department, School of Business, Southern Illinois University Edwardsville, \\ Edwardsville, IL 62026-1102, USA \\ ${ }^{\mathrm{b}}$ The Center for European Integration Studies (ZEI), Bonn, Germany \\ ${ }^{\mathrm{c}}$ The Emerging Markets Group, London, UK \\ ${ }^{\mathrm{d}}$ The William Davidson Institute (WDI), MI, USA \\ 'Department of Economics, Bilkent University, Bilkent, 06800 Ankara, Turkey
}

Received 25 February 2004; accepted 20 November 2006

Available online 11 January 2007

\begin{abstract}
This paper derives a stochastic endogenous growth model to investigate the impact of European Union (EU) integration on convergence and productivity growth. The theoretical model implies both temporary and permanent positive effects of the integration process. The empirical part of the analysis uses structural break tests and data envelopment analysis to examine the accession process of five recent members to the EU15. The results show (i) endogenously identified accession dates as structural breaks, (ii) improved rates of productivity growth after accession over and above the Union benchmark level, and (iii) increased pace of overall growth due to capital accumulation as a result of institutional features of the Union such as Structural and Cohesion Funds. These findings support the theoretical model, implying that economic integration is beneficial for member countries, especially from a long-run perspective, and Cohesion and Structural funds help the new members catch up with the core-EU members' standard of living.
\end{abstract}

(C) 2006 Elsevier B.V. All rights reserved.

JEL classification: $\mathrm{F} 02 ; \mathrm{O} 47 ; \mathrm{O} 52 ; \mathrm{C} 22 ; \mathrm{C} 23$

Keywords: Integration; Growth; European Union; Structural break; Productivity; Efficiency; Structural and cohesion funds

\footnotetext{
${ }^{*}$ Corresponding author. Tel.: + 903122901643 ; fax: + 903122665140.

E-mail addresses: akutan@siue.edu (A.M. Kutan), tyigit@bilkent.edu.tr (T.M. Yigit).
} 


\section{Introduction}

In an age where many countries strive to join the European Union (EU) although countries like Switzerland and Norway constantly refuse to join, it is natural to ask whether EU membership has any long and/or short run benefits. Although the effects of joining an economic union have been studied extensively because of their implications for policymakers, it is quite difficult to measure the overall benefits of integration because it impacts many aspects of an economy. Even studies focusing on a specific effect of integration on growth have provided incomplete conclusions because they had to use proxies to represent the integration process. ${ }^{1}$ These proxies, such as trade, foreign direct investment (FDI), research and development (R\&D) expenditures, number of patents issued, and time series dummies are limited in scope, and hence they can only partially capture the overall impact of joining a union. Besides being unobservable, such proxies can lead to false inferences, because of endogeneity and causality issues. ${ }^{2}$ While the biggest benefit one expects from entering into a union like the EU is the rise in living standards through a high level of cooperation in all economic, political and institutional aspects, it is very difficult to envisage a proxy for such a complex network of cooperation and sharing of knowledge.

In this paper, we investigate the benefits of integration on economic growth, productivity and convergence, specifically focusing on knowledge spillovers. We employ alternative ways to detect and decompose these unobservable benefits without restricting ourselves to one specific proxy. To accomplish our objective of observing the outcome of broad and multifaceted institutional and technological cooperation, we propose to focus on how the growth process changes following the EU membership. Detecting such changes may not be sufficient, however, because they could be to the result of other factors. Hence, in order to connect the sharing of knowledge to growth, one needs to measure changes in productive as well as technological capabilities. In this paper, we aim to obtain evidence of such abstract benefits by decomposing significant developments in growth into observable changes in economic variables (inputs) and the not-so-observable changes in productivity and efficiency. We also control for the institutional facet of integration, namely the net budget transfers such as the Structural and Cohesion Funds, so that the effects of knowledge spillovers and integration on growth could be separated from the effects of such capital flows.

More specifically, our research extends the stochastic endogenous growth literature to capture the impact of economic integration on convergence and productivity growth. Applying Rivera-Batiz and Romer's (1991, RB-R hereafter) analytical hypothesis that integration leads to sharing of knowledge and technology, we develop a new theoretical framework to capture the effects of integration on growth. Using RB-R's hypothesis, we are able to extend the work of Lee, Pesaran, and Smith (1997, LPS hereafter) to examine changes in productivity and convergence rate after the accession to a union. We subsequently test the theoretical claims of our model using a battery of structural break

\footnotetext{
${ }^{1}$ Many examples are cited in the next section.

${ }^{2}$ Regarding estimation problems such as causality and endogeneity, Frankel and Romer (1999) argue that trade variables employed in previous growth studies may be endogenous. Walde and Wood (2004) conclude that the existing literature is "quiet" on the direction of the true causality in the trade-growth relationship. Yanikkaya (2003) reports similar findings.
} 
tests and data envelopment analyses to find confirmation for strong positive response to integration on a number of dimensions. In a nutshell, our findings show that integration into an economic union has direct (capital accumulation) and indirect (technology transfer) effects on a country's growth process. The institutional aspects of the EU integration, such as the Structural and Cohesion Funds programme, also seem to play an effective role in furthering economic convergence and growth.

The paper is organized as follows. In Section 2, we briefly review the earlier work and discuss our contribution in light of these studies. Section 3 sets out our theoretical model. We describe our estimation technique in Section 4 while data description and empirical results are given in Section 5. The last section provides a summary of the key findings of the paper and its policy implications.

\section{Benefits of economic integration}

Early studies of the effects of regional integration rely on foreign trade variables to capture the effects of integration. Baldwin and Seghezza (1996) examine the benefits of integration by employing trade barriers both in growth and investment equations but find no evidence of a technology-boosting impact. However, they note that the investment coefficient in the growth equation is likely to pick up some of the technology impact on growth, and, thus, it is hardly possible to isolate the trade impact from innovation. Baldwin (2000) reports that trade policies do not have a significant negative effect on GDP or productivity growth. Using time dummies and the experience of both European Community (EC) and European Free Trade Area (EFTA) countries, Henrekson et al. (1997) examine the role of trade and institutional integration on economic growth. They find a positive impact of European integration on growth suggested by a statistically significant coefficient for the EC/EFTA dummy variable. ${ }^{3}$

The literature on the direct effects of trade has been extended to allow trade to facilitate technology transfer. Grossman and Helpman (1991) and Coe and Helpman (1995, CH henceforth) view business innovation as an important element of technical progress. While the former study shows that it is difficult to draw conclusions on the growth effects of trade restrictions, the latter claims that a country's factor productivity depends not only on its own but also on its main trading partners' R\&D capital stocks. Using R\&D expenditures as a proxy for knowledge, they find a significant link between productivity and R\&D capital stocks in EU and other industrial countries, indicating significant international R\&D spillovers. Kao et al. (1999) reconsider CH's results by utilizing panel cointegration tests. They find that small economies tend to benefit more from R\&D spillovers than do large economies and that the beneficial impact of trade is not as high as CH's estimates. Engelbrecht (1997) also extends CH's study by including a human capital variable to capture innovation, which he argues may not be accounted solely by R\&D capital stock. He finds that human capital has a significant effect on economic growth besides R\&D. Using data for OECD countries, Griffith et al. (2004) confirm the importance of R\&D and

\footnotetext{
${ }^{3}$ More recent studies focus on the new member states. Crespo-Cuaresma et al. (2002) report that the length of EU membership has a significant and positive effect on growth, and it is higher for poorer countries, suggesting an asymmetric impact of EU membership. Martin and Velázquez (2001), Wagner and Hlouskova (2002) and Boldrin and Canova (2003) derive lessons from the experience of the previous accession countries for the new member states.
} 
human capital on growth. Their results also indicate that R\&D is important not only for innovation but also for technological catch-up.

A second popular stand-in for integration is FDI, which was used by Dohrn et al. (2001) to detect a positive correlation between the economic growth and FDI per capita. However, they argue that the direction of causation is difficult to establish. ${ }^{4}$ Indeed, Gao (2005) shows that both FDI and growth respond endogenously to economic integration, hence any relationship between FDI and growth does not necessarily imply a meaningful causality link. Similarly, Saggi (2000) argues that convincing evidence of the superiority of FDI as the vehicle of technology transfers is hard to find. Conversely, other studies emphasize the importance of spillovers from inward investment to technical progress in EU economies (Barrell and Pain, 1997, 1999). In short, the literature suggests that it is difficult to estimate the impact of integration on growth by relying on proxies for integration.

We deal with these legitimate concerns by providing an alternative approach to estimate the unobservable process of "innovation and exchange of ideas". To do so, we extend the stochastic neoclassical growth model of LPS by implementing the 'integration parameter' of RB-R to analyze the effects of EU accession. We assume that integration process allows access to a wider body of knowledge and hence leads to higher productivity by enhancing the effectiveness of labor, also speeding up the convergence process. Using a series of structural break tests and a data envelopment exercise, we validate the implications of our theoretical model. In this respect, we endogenously identify accession dates using structural breaks, make inferences about permanent and temporary effects of integration, and isolate technological effects of integration (i.e., sharing of knowledge). In these tests, we also control for the turbulence in the exchange rate mechanism (ERM) of the Union and the completion of the Single Market that took place in 1992.

Another important aspect of our paper is that we control for the institutional facet of integration, namely the net budget transfers such as the Structural and Cohesion Funds, so that the effects of knowledge integration on growth could be separated from the effects of such capital flows. The Structural and Cohesion Funds, which account for about one third of the Union's budget, provide support to improve infrastructure and the telecommunications network, develop human resources, and fund research and development in order to reduce regional disparities in the Union. Given the recent enlargement of the Union to 25 member states on May 2004 and the current enlargement plans in the near future, the impact of such funds on economic convergence and growth in the region has become a highly debated issue. As the current round of Structural and Cohesion Funds programmes are about to be completed soon, the European Commission has recently announced its plans for the next round for the period of 2007-2013. Negations are now under way between member states and EU to decide on regions that would be eligible for funds.

Empirical evidence on the effectiveness of Structural and Cohesion Funds on growth can best be described as mixed, however. Besides the work of the European Commission (2001), Fayolle and Lecuyer (2000), Solanes and Ramon (2002) and Beugelsdijk and Eijffinger (2003) find a statistically significant effect of Structural and Cohesion Funds on

\footnotetext{
${ }^{4}$ As far as cross-country studies, Durham (2004), Carkovic and Levine (2002) and Alfaro et al. (2004) find that it is difficult to find a robust relationship between FDI and economic growth. Furthermore, they show that the effect of FDI on growth depends on the "absorptive capacity" of the home country. Borensztein et al. (1998) argue that FDI's growth impact goes beyond its influence on the total investment; it also depends on the stock of human capital in that country, suggesting that the benefits of higher FDI are realized not only through capital accumulation, but also through efficiency gains.
} 
growth and convergence. However, Boldrin and Canova (2003) conclude that these policies do not foster economic growth. The results are also shown to be sensitive to the assumption made about country-specific steady states (Ederveen and Gorter, 2002). Our paper contributes to this literature as well by providing empirical evidence whether such funds can enhance economic growth in the Union.

\section{Theoretical framework}

Following RB-R, we assume that economic integration leads to a long-run growth rate increase in the member countries, while improvements in trade can have only transitory effects. Economic integration between developed economies enables goods and ideas to flow from one country to the next much more easily, enhancing growth over time. The production function used in $\mathrm{RB}-\mathrm{R}$ is

$$
Y=H^{\alpha} L^{\beta} \int_{0}^{Z} x(i)^{1-\alpha-\beta} \mathrm{d} i,
$$

where $H$ is human capital and $Z$ is the capital enhancing innovation, capital equals $\int_{0}^{Z} x(i) \mathrm{d} i$, and $i$ is the index of the most recently invented good. According to their assumptions, ${ }^{5}$ patents for innovations, which are normally traded, are shared after integration; $Z$ of cooperating countries increases at a low cost, the model becomes symmetric and enables us to substitute $K / Z$ for $x(i)$. We simplify the notation by adopting exogenous productivity growth, $A$, as in LPS, rather than growth of human capital, $H$. LPS develop a stochastic neoclassical growth model to investigate the biases in convergence rate estimates when productivity growth is ignored. In our research, we utilize the same stochastic model but we incorporate in it the integration parameter of $\mathrm{RB}-\mathrm{R}$, yielding the following reduced form production function

$$
Y_{i t}=K_{i t}^{\alpha}\left(A_{i t} L_{i t} Z_{i t}\right)^{1-\alpha}, \quad \text { where } 0<\alpha<1 .
$$

In such a formulation, the body of knowledge, $Z$, is an unobservable stochastic process, and it is therefore difficult to identify its determinants in practice although factors such as the volume of international trade, FDI, R\&D, etc., should clearly be seen as key drivers. In this regard, our model encompasses as special cases the previous research that used proxies for $Z$ (CH, 1995; Griffith et al., 2004). We aim to find a more general and comprehensive effect of integration, namely the sharing of knowledge among members of the integration scheme because using $R \& D$ stock as a proxy may be too restrictive or prone to mismeasurement due to possible overlaps with the flow of funds between the member countries. Nevertheless, as in previous studies, we seek to uncover the improvements in $Z$ that are expected after integration via better dissemination of ideas and technologies through numerous channels that are either unobservable or difficult to proxy. In an attempt to better capture the integration effects associated with the diffusion of ideas, we control for the well publicized and widely debated effects of convergence-directed Structural and Cohesion Funds as well as of FDI inflows on growth. ${ }^{6}$ In such a fluid

\footnotetext{
${ }^{5}$ Capital goods are substitutes for consumption goods, so their prices are determined by technology.

${ }^{6}$ As mentioned earlier, the empirical evidence on the impact of cohesion policy on convergence and growth is mixed. The results are sensitive to the assumption as to how and where such funds are used, suggesting that the empirical results can best be interpreted as showing a "potential" impact on growth (Ederveen and Gorter, 2002).
} 
environment, where membership brings not only sharing of technology and ideas but also large inflows of capital in the form of structural funds, FDI, etc., our model allows for the possibility of short run or temporary inefficiencies in resource allocation. ${ }^{7}$ Not allowing for such inefficiencies may lead to false inferences about total factor productivity (TFP). Hence, Eq. (2) is modified to

$$
\frac{Y_{i t}}{\theta_{i t}}=K_{i t}^{\alpha}\left(A_{i t} L_{i t} Z_{i t}\right)^{1-\alpha},
$$

where values of $\theta_{i t}$ less than 1 indicate instances of inefficiency, in which the production level is below the efficient frontier. One should note that $\theta_{i t}$ can be moved to inside the parentheses and interpreted as efficiency of labor or as shown below enter the model as inefficiency in investment. The empirical section elaborates on how the measurement of the inefficiency parameter is separated from that of $A$.

Capital formation is given by

$$
\begin{aligned}
K_{i t} & =I_{i, t-1}+(1-\delta) K_{i, t-1}, \\
I_{i t} & =\left(s_{i}+f_{i}\right) \frac{Y_{i t}}{\theta_{i t}},
\end{aligned}
$$

where $s_{i}$ and $\delta$ are the domestic savings and depreciation rates, $\theta_{i t}$ is the efficiency in production or investment (see Greenwood et al., 1997; Hercowitz, 1998; Krussel,1998), and $f_{i}$ represents the inflow (outflow when negative) of foreign savings in the form of Structural and Cohesion Funds. We treat these funds differently from other capital flows. Following the European Commission (2001), we assume these funds are directed to investment projects that have positive payoffs. Because the income level of the joining country determines $f_{i}$, these inflows will be higher for laggard countries. Furthermore, they will tend to raise the benefits for these "new" members, who had lower than average per capita GDP levels. Then, the evolution of the capital stock is

$$
\Delta \log \left(k_{i t}\right)=-\Delta \log \left(A_{i t} L_{i t} Z_{i t}\right)+\log \left(\frac{\left(s_{i}+f_{i}\right)}{\theta_{i t-1}} k_{i, t-1}^{-(1-\alpha)}+1-\delta\right),
$$

where $k_{i t}=K_{i t} / A_{i t} L_{i t} Z_{i t}$ is the effective capital because enhancements in capital, $Z$, increase the effectiveness of labor. We follow the stochastic path of the solution to this growth problem proposed by LPS subject to the following

$$
\begin{aligned}
& \log \left(A_{i t}\right)=a_{0 i}+g_{i} t+u_{a i t}, \\
& u_{a i t}=\rho_{a i} u_{a i, t-1}+\varepsilon_{a i t}, \quad \text { where }\left|\rho_{a i}\right| \leqslant 1, \\
& \log \left(L_{i t}\right)=l_{0 i}+n_{i} t+u_{l i t}, \\
& u_{l i t}=\rho_{l i} u_{l i, t-1}+\varepsilon_{\text {lit }}, \quad \text { where }\left|\rho_{l i}\right| \leqslant 1,
\end{aligned}
$$

where the technology shock, $u_{\text {ait }}$, captures exogenous factors that might shift TFP (other than growth of technology, $g_{i}$ ), and the employment shock, $u_{l i t}$, represents labor market

\section{(footnote continued)}

For example, the European Commission (2001) assumes the funds add to (productive) public investment. For a survey of the literature on the effects of cohesion policy on growth and convergence, see Ederveen et al. (2002).

${ }^{7}$ Inefficiencies occur if observed factor income shares are not the cost-minimizing factor income shares, implying that factors are not paid the value of their marginal product as assumed in standard growth accounting approaches. 
effects other than population growth, $n_{i}$. Based on the "knowledge driven model" of RB-R, we add the approximate stochastic process for $Z_{i t}$

$$
\log \left(Z_{i t}\right)=z_{i 0}+\zeta_{i} t+u_{z i t}
$$

where $\zeta_{i}$ is the rate of innovation. We stress that we thus separate standard factor productivity growth into two components, exogenous productivity growth, $g_{i}$, and capital enhancing innovations, $\zeta_{i}$, diffused through a range of economic interactions with other members of the Union. We expect that the mean of the regionally influenced productivity growth rate, $\bar{g}$, is approximately equal to the exogenous productivity growth of the integrated countries. The rate of diffusion of innovations, $\zeta_{i}$, represents the information inflow into the new member country, which then raises the new member's productivity growth over and above that of the Union. In essence, the integration process fosters convergence by improving the new members' productivity growth rates to levels higher than that of the Union $\left(g_{i}+\zeta_{i}>\bar{g}\right)$. The empirical section attempts to quantify the effect of the sharing of knowledge on new members' growth by separating the exogenous (or regional) productivity growth from the integration related one, $\zeta_{i}$. We do not impose a dynamic structure for the efficiency term, $\theta_{i t}$, since its time path is likely to be "noisy" due to the lumpiness of fund inflows and as well as large differences in the speed with which different types of fund inflows are absorbed into the capital stock. A final assumption we make in Eq. (9) is the identical autocorrelation in $u_{z i t}$ as in the technological process, $u_{\text {ait }}$.

Using the fact that expected change in effective capital is zero in the steady state (omitting the subscript $i$ ), we obtain

$$
n+g+\zeta=E\left[\log \left(\frac{(s+f)}{\theta_{\infty}} k_{\infty}^{-(1-\alpha)}+1-\delta\right)\right]
$$

where $k_{\infty}$ is the random variable that underlies the steady-state distribution of $k_{t}$ and $\theta_{\infty}=1$ is the steady state level of efficiency.

Utilizing Jensen's inequality, this term equals

$$
n+g+\zeta=\log \left((s+f) \mathrm{e}^{-(1-\alpha) E\left[\log \left(k_{\infty}\right)\right]}+1-\delta\right)+h .
$$

The approximation of the nonlinear term in this equation around $E\left[\log \left(k_{\infty}\right)\right]$ yields

$$
\log \left((s+f) k_{t-1}^{-(1-\alpha)}+1-\delta\right)=\gamma-(1-\lambda) \log k_{t-1}+\xi_{t},
$$

where, for small values of $n, g, \zeta, \delta$, and $h$,

$$
1-\lambda \approx(1-\alpha)(n+g+\delta+\zeta-h)
$$

and

$$
\gamma \approx(n+g+\zeta-h)+(n+g+\zeta+\delta-h)[\log (s+f)-\log (n+g+\delta+\zeta-h)] .
$$

In the deterministic version of the model, the linearization is around the steady state, where $k$ and the $u$ 's are assumed to be zero. For $h=0$, the term $(1-\lambda)$ is the measure of beta convergence. Defining log output per capita as

$$
\log (Y / L)=x_{t}=a_{t}+z_{t}+\alpha \log \left(k_{t}\right),
$$


where $a_{t}=\left(A_{t}\right)$ and $z_{t}=\log \left(Z_{t}\right)$, and thus,

$$
\Delta x_{t}=\Delta a_{t}+\Delta z_{t}+\alpha\left[-(n+g+\zeta)-\Delta u_{t}+\gamma-(1-\lambda) \frac{x_{t-1}-a_{0}-z_{0}-(g+\zeta)(t-1)-u_{a}-u_{z}}{\alpha}\right] .
$$

Using Eqs. (5)-(9), we can rewrite Eq. (16) as

$$
x_{t}=\mu+(1-\lambda)(g+\zeta) t+\lambda x_{t-1}+e_{t},
$$

where

$$
\mu=\lambda(g+\zeta)-\alpha(n+g+\zeta)+\alpha \gamma+(1-\lambda)\left(a_{0}+z_{0}\right)
$$

and

$$
\begin{aligned}
& e_{t}=\Delta u_{a t}+\Delta u_{z t}-\alpha \Delta u_{t}+(1-\lambda)\left(u_{a t-1}+u_{z t-1}\right), \\
& \Delta u_{t}=\Delta u_{a t}+\Delta u_{l t}+\Delta u_{z t} .
\end{aligned}
$$

In the context of the Solow growth model $(0<\alpha<1)$, output will have a unit root only if $e_{t}$ has a unit root. LPS show that the unit root in $e$ depends only on the unit root in the technology shock, in their case, $u_{a}$. In our model, it depends on the unit root in the joint shock component, namely, $u_{a}$ and $u_{z}$. Therefore, assuming $\rho_{l}=1$ and $\rho_{a}=\rho$, as in LPS, and changing the notation for the autocorrelation in $u_{a}{ }^{8}$, we derive our testable equation

$$
x_{t}=\left[(1-\rho) \mu+(1-\lambda)(g+\zeta) \rho+(1-\lambda)(1-\rho)(g+\zeta) t+(\lambda+\rho) x_{t-1}-\lambda \rho x_{t-2}+(1-\psi L) \varepsilon_{t},\right.
$$

where $\varepsilon_{t}$ is a composite error term ${ }^{9}$ from Eqs. (6), (8), and (9), and $\psi$ is a nonlinear function of variances/covariances of technology, employment, innovations, and other parameters of the model. With additional assumptions, LPS show that this equation can be written in the form

$$
(1-\lambda L)(1-\rho L) x_{t}=[(1-\rho) \mu+(1-\lambda)(g+\zeta) \rho]+(1-\lambda)(1-\rho)(g+\zeta) t+(1-\psi L) \varepsilon_{t} .
$$

The main implication of the LPS model, where the $\zeta$ is not accounted for, is that countries would have different speeds of convergence and productivity growth rates; hence, the standard estimation techniques such as augmented Dickey-Fuller (ADF), would not produce reliable inferences about the speeds of convergence. ${ }^{10}$ We use a similar model and show that integration has an impact on (i) the rate of growth by increasing the steady state value, the first term on the right hand side of Eq. (20), (ii) on the convergence rate in Eq. (13), and (iii) on productivity growth, the coefficient of the deterministic trend in Eq. (20).

As in the LPS methodology, a further simplification of the testable specification is possible by assuming that the convergence rate and the autocorrelation in technology

\footnotetext{
${ }^{8}$ This simplification of the autocorrelation term will not matter for the estimation procedure because our methodology allows for a wide range of serial correlations in the error term, even in the unit root case.

${ }^{9}$ The first order moving average form will depend on certain restrictions on the correlation between the employment shock and the joint technology shock.

${ }^{10}$ This is because the autoregressive coefficient tested is the product of many variables such as $\rho, \alpha, g, n, \delta, h$, and $\zeta$ with our addition, and thus the existence of a unit root in output is not necessarily evidence against the neoclassical model, because it can be caused by a unit root in the technology process $(\rho=1)$.
} 
approximately equal the moving average coefficient, ${ }^{11}(1-\lambda \simeq 1-\rho \simeq 1-\psi)$, which transforms the system into

$$
x_{t}=\mu+(1-\lambda)(g+\zeta) t+\lambda x_{t-1}+\varepsilon_{t},
$$

where

$$
\mu=\lambda(g+\zeta)-\alpha h+(1-\lambda)\left\{a_{0}+z_{0}+(\alpha / 1-\alpha)[\log (s+f)-\log (n+g+\zeta+\delta-h)\} .\right.
$$

This system is a modified version of the frequently adopted method of convergence tests with the addition of the possibility of changes in the steady state term and in productivity growth. To estimate $\lambda$ and $(g+\zeta)$ separately, LPS suggest rewriting the equation as

$$
\begin{aligned}
& x_{i t}=c_{i}+\left(g_{i}+\zeta_{i}\right) t+u_{i t}, \\
& u_{i t}=\lambda_{i} u_{i, t-1}+\eta_{i t},
\end{aligned}
$$

giving us our final estimation equation. Separating $\lambda$ and $(g+\zeta)$ prevents any false inferences about convergence that could result from the presence of a unit root in productivity growth. Using the fitted values of these equations, we obtain $\mu_{i}$ by noting that

$$
\mu_{i}=\left(1-\lambda_{i}\right) c_{i}+\lambda_{i}\left(g_{i}+\zeta_{i}\right)
$$

It is apparent that one cannot identify both $g_{i}$ and $\zeta_{i}$ from these specifications, but a sudden change in the integration process could generate a structural shift in per capita GDP. Hence, searching for structural breaks in all of our parameters is a major part of our empirical methodology. To be precise, we expect to find statistically significant breaks in the steady state due to an increase in the investment rate, $(s+f)$, and in both productivity growth and convergence rates due to integration, $\zeta_{i}$.

The next section describes our further attempts at identifying $\zeta_{i}$. In the second part of our estimation section, we examine TFP growth in more detail in an attempt to capture the pure impact of integration on productivity and to separate its effect from that of other factors.

\section{Empirical methodology}

In our estimations we allow for differences in the country characteristics, but we are careful to avoid confusing the effects of regional events from those of integration. We use a benchmark country already in the Union to remove the regional effects. This allows us to evaluate the pure impact of the integration process, netting out the impact of events affecting the whole region. We use France as the benchmark country to represent the EU core. $^{12}$ Therefore, the estimated system given by Eq. (24) becomes

$$
\begin{aligned}
& x_{i t}-\bar{x}_{t}=\left(c_{i}-\bar{c}\right)+\left(g_{i}+\zeta_{i}-\bar{g}\right) t+\left(u_{i t}-\bar{u}_{t}\right), \\
& \left(u_{i t}-\bar{u}_{t}\right)=\lambda_{i}\left(u_{i, t-1}-\bar{u}_{t-1}\right)+\left(\eta_{i t}-\bar{\eta}_{t}\right),
\end{aligned}
$$

\footnotetext{
${ }^{11}$ This is a very important assumption for the accurate measurement of the convergence rate because changes in the convergence rate could be driven by changes in the serial correlation in technology. We rely on LPS's (1997) empirical finding of this equality and identifying only eight exceptions to it in a sample of more than 100 countries.

${ }^{12} \mathrm{We}$ do not use Germany because of the potential structural break in data due to its unification with East Germany.
} 
where the benchmark (French) coefficients are obtained from a similar regression

$$
\begin{aligned}
& \bar{x}_{t}=\bar{c}+\bar{g} t+\bar{u}, \\
& \bar{u}_{t}=\lambda \bar{u}_{t-1}+\bar{\eta}_{t} .
\end{aligned}
$$

Note that Eq. (27) would not contain a structural break caused by integration. This is mainly because we use a country that had already joined the Union much earlier than did the newcomers, and thus garnered the benefits and experienced the structural breaks before the time covered by this study. An additional advantage of subtracting the benchmark from each new member prior to the structural break tests is that we get estimates of the net impact of integration, $\zeta_{i}$. Since the expected value of $g_{i}$ is $\bar{g}$, the expected slope coefficient in Eq. (26) will be equal to $\zeta_{i}{ }^{13}$

In the initial part of our estimations, we use a filtering process, which initially extracts information on the levels of, and breaks in, the deterministic trend components of the GDP per capita difference from the French benchmark and then estimates the convergence rate. We start by identifying the parameters of Eq. (26) with the help of structural break tests. We estimate the impact of integration on the de-trended per capita data, using France to represent the common European trend. However, a system such as Eq. (26) is difficult to estimate, especially under the possibility of the existence of a unit root in the error process $u_{i t}$ or of structural breaks in the parameters $c_{i}, \lambda_{i}$ and $g_{i}$. Therefore, we first need to ensure that the inference we get on the parameters under high serial correlation (or breaks) in the error term is correct. To do so, we use the methodology proposed by Vogelsang (1998). Using the trend function hypothesis he developed, we divide our estimation into two parts, namely the estimation of the levels and breaks in the parameters $c_{i}$ and $g_{i}$ in the first stage, and the convergence coefficient $\lambda_{i}$ in the second. Vogelsang's (2001) more recent extension allows for a single structural break by modifying the earlier statistics after including the possibility of shifts in the trend function.

$$
y_{t}=\mu_{1} D U_{1 t}+\mu_{2} D U_{2 t}+\delta_{1} D T_{1 t}+\delta_{2} D T_{2 t}+u_{t},
$$

where $D U_{1 t}=1$ if $t \leqslant T_{b}$ (the break date) and zero otherwise, $D U_{2 t}=1$ if $t>T_{b}$ and zero otherwise, $D T_{1 t}=t$ if $t \leqslant T_{b}$ and zero otherwise, and finally $D T_{2 t}=t-T_{b}$ if $t>T_{b}$ and zero otherwise. Of the two possible versions of the test, we favor the one that detects breaks endogenously, not imposing a break date in the estimations. Finding breaks endogenously around the times of accession is a direct evidence in support of our theory since they verify the existence of the productivity effects mentioned in Eq. (24). Appendix A.1, provides more detailed information on Vogelsang's methodologies.

Despite their flexibility in allowing for various types of serial correlation in the error term, the Vogelsang tests are limited for the purposes of our study because they allow for only a single break and cannot analyze breaks in the autoregressive parameters, in our case, the convergence rate. Because our model foresees changes in the mean, trend, and the autoregressive parameter, we supplement Vogelsang's test results with the stochastic multiple-break test developed by Bai and Perron (1998, BP henceforth).

\footnotetext{
${ }^{13}$ If needed, the coefficient values in Eq. (24) can be obtained by adding the estimates of Eq. (26) to those of Eq. (27).
} 
The general form of the BP (1998) methodology considers the following multiple structural break model, with $m$ breaks $(m+1$ regimes)

$$
y_{t}=x_{t}^{\prime} \gamma_{j}+u_{t}
$$

for $t=T_{j-1}+1, \ldots, T_{j}$ and $j=1, \ldots, m+1 . y_{t}$ is the observed dependent variable at time $t ; x_{t}(q \times 1)$ is the vector of covariates, and $\gamma_{j}$ is the corresponding vector of coefficients, and $u_{t}$ is the disturbance term at time $t$. The break points $\left(T_{j}\right)$ are treated as unknown, and are estimated together with the unknown coefficients when $T$ observations are available. Even though the definition of $z_{t}$ in the BP test is general enough to allow the testing of breaks in the mean, trend, and the autoregressive parameters simultaneously, we opt for a two-stage method for two reasons. The first is that the BP test performs poorly in detecting multiple structural changes in the trending terms and possible unit roots. ${ }^{14}$ The second reason is that the analysis of the autoregressive form in Eq. (22) would yield incorrect inferences about the structural break of the trend parameter due to its nonlinear nature in the parameters of interest, $\lambda$ and $g+\zeta$. In this two-stage method, we first utilize the parameter estimates from the Stage 1 regressions (Vogelsang, 2001) to de-trend the GDP per capita differences from benchmark. Then, in Stage 2, we concentrate on the underlying autoregressive process of the residual series. The benefit of the two-stage estimation mechanism is that it allows us to use a method that derives inferences about a deterministic (single) trend break regardless of the serial correlation in the error term, while the second stage allows the reliable measurement of multiple breaks in the autoregressive error term. More information on BP's methodology can be found in Appendix A.2.

Even though the structural break tests allow us to test the predictions of our theoretical model, it is not clear whether the effects we find are caused by the dispersion of knowledge or accumulation of capital via structural fund payments. In other words, the breaks we find in the growth trend could be due to (i) the countries' own capital accumulation and their transition to the new steady state or (ii) due to endogenous growth in the steady state due to the technological diffusion of ideas and knowledge. In order to better identify the underlying reason for our structural break results, as a final part of our estimations, we propose to decompose the production process of sample countries to measure their Malmquist productivity indexes.

Introduced by Caves et al. (1982), and later developed by Färe et al. (1994), Malmquist indexes can be used to measure productivity by using information on only input and output quantities. Their non-parametric Malmquist measure relies on constructing a bestpractice frontier for the whole sample and then computing the distance of individual observations from that frontier. Using non-parametric programming, the index can be partitioned exhaustively into useful component measures, namely technical change (shift of frontier or $\zeta$ in our analysis) and efficiency change (change of proximity to frontier or $\theta$ in our analysis) components. By doing so, this methodology not only allows for identification of countries that are below their frontier, ${ }^{15}$ but also performs growth accounting without

\footnotetext{
${ }^{14}$ For instance, the restrictions that Barrell and Pain (1997) mention on the application of their methodology are that (a) one should not allow for a unit root, and that (b) when a lagged dependent variable is used, autocorrelation in the error term cannot be allowed. Despite their claim of being able to include trending terms in the regression, estimating a pure structural break model, in which all the coefficients could change, generated nonconvergence in our estimations (especially for the trend variable).

${ }^{15} \mathrm{We}$ allow for temporary imbalances in production process due to increased capital flows to and from these countries, possibly distorting usage of optimizing factor values during integration. Not allowing for such imbalances may lead to false inference on TFP measures.
} 
the specification of an explicit functional form. In short, the change in actual output can be divided into observable changes in inputs $(\Delta K, \Delta L)$, changes in the efficiency parameter $(\Delta \theta)$, and technological innovations $(\Delta A=Z)$. This division helps to separate the sources of growth in GDP per capita, providing us with a more detailed picture of the underlying causes. More detail on the Malmquist index is available in Appendix A.3.

To summarize, the combination of our theoretical framework and empirical methodology contributes to the literature on conditional convergence and the growth effects of technological spillovers. ${ }^{16}$ First, we utilize a less restrictive definition of integration than do previous studies, so we are more ambitious in trying to obtain inferences about variables that are not observable, such as technological innovations, $Z$, and efficiency, $\theta$. By using a stochastic endogenous-growth model, we are able to separately analyze the impact of integration on the steady state, productivity growth and the convergence rate. The model shows that the sharing of a wider body of knowledge base results in changes in all three. Second, we test for the significance of these effects by inspecting the structural breaks in these parameters originating from integration into an economic union. Third, data envelopment analyses (or the Malmquist index) help us distinguish the productivity impact of integration from temporary movements in the growth rate, such as changes in input accumulation patterns and the transitions from one steady state to another. Not accounting for such short-run movements may complicate the measurement of productivity, as in $\mathrm{CH}$ (1995), to be inaccurate. Fourth, we allow for a spectrum of convergence rates, including a no-convergence scenario, by considering unrestricted forms of serial correlation in the $u_{i t}$ of Eq. (24). Finally, by incorporating structural funds explicitly into the model, we attempt to account for the institutional benefits of integration. The next section elaborates on our data and the empirical results we obtain from the application of the methodologies described above.

\section{Empirical results}

\subsection{Data}

We employ two separate datasets, covering the last five members to join the EU15, namely, Spain, Portugal, Austria, Finland, and Sweden, along with France as the benchmark country. All data are quarterly and the sample period runs from 1980:Q1 to 2004:Q4. The first data set, which consists of GDP per capita, is obtained from International Financial Statistics (IFS) of the IMF. We construct real GDP per capita data in Euros based on the European Currency Unit (ECU) and later Euro exchange rates. Since the classical definition of convergence and Eq. (15) refer to the log of real GDP per capita, we take the natural logarithm of all the series. The second data set, which includes annual capital stock, GDP (except for Sweden all in fixed euros) and employment series, is obtained from the Total Economy Growth Accounting Database of the Groningen Growth and Development Center and The Conference Board. The data set is compiled mostly from OECD National Accounts. ${ }^{17}$ Capital stock and GDP data for Sweden are converted into Euros, using the IFS exchange rate series mentioned above.

\footnotetext{
${ }^{16}$ See Grossman and Helpman (1991) and Coe and Helpman (1995).

${ }^{17}$ Further details on the source of the data can be found in http://www.ggdc.net/dseries/Data/Growthaccounting/sources_TEG05.pdf.
} 
Table 1

Endogenous PSW break test of the deterministic trend of country GDP/capita (difference from the French Benchmark)

\begin{tabular}{lllllll}
\hline Countries & Pre-mean & Pre-trend & Post-mean & Post-trend & Estimated break date & Accession date \\
\hline Austria & $-\mathbf{0 . 1 6 5} * *$ & $\mathbf{0 . 0 0 4} * *$ & $\mathbf{0 . 0 6 9} *$ & 0.000 & 1996Q3 & 1995Q1 \\
Finland & -0.059 & $\mathbf{0 . 0 0 8} * *$ & $-\mathbf{0 . 1 5 0} * *$ & $\mathbf{0 . 0 0 5} * *$ & 1991Q3 & 1995Q1 \\
Portugal & $-\mathbf{1 . 6 2 8}^{* *}$ & $\mathbf{0 . 0 1 0} * *$ & $-\mathbf{0 . 9 9 4} * *$ & $\mathbf{0 . 0 0 6} * *$ & 1990Q3 & 1986Q1 \\
Spain & $-\mathbf{0 . 7 6 2} * *$ & 0.001 & $-\mathbf{0 . 5 3 8 * *}$ & 0.002 & 1988Q1 & 1986Q1 \\
Sweden & $\mathbf{0 . 1 7 3} * *$ & 0.002 & 0.068 & 0.002 & 1992Q3 & 1995Q1
\end{tabular}

Notes: Reported estimates come from the estimation of Eq. (28) using the Vogelsang (2001) test on individual GDP per capita differences from France. Pre-mean and post-mean values represent mean deviation in logs from French GDP per capita before and after the accession periods, respectively. **(*) indicates $95 \%(90 \%)$ significance levels. Therefore, insignificance in mean or trend indicates same mean or trend with that of France. Estimated break date reports the endogenously attained date while the last column shows the accession date of each country.

\subsection{Structural break tests results}

As mentioned earlier, our initial results are derived from a filtering process that initially extracts information on the levels and breaks of the deterministic trend components of the GDP per capita difference from the French benchmark and then obtains inferences on the convergence rate. Table 1 displays the results from a structural break estimation of the deterministic trend (Vogelsang, 2001). The results seem puzzling for some countries because the endogenously determined break dates are at varying points in the datasets; only Austria seems to have a break date at its accession period. We believe the main reason for these findings lies in the events that took place around 1992, in particular the ERM crisis. ${ }^{18}$ Our simulation results, which are not reported here for space considerations, show that when multiple breaks exist, single break tests used in our analysis tend to find the break point in between the two breaks. ${ }^{19}$ Because the multiple break methodology of Bai and Perron (1998) performs poorly in detecting trend breaks with possible nonstationarity, we decrease the number of breaks in the data by concentrating on events other than the ERM crisis that occurred in the 25 years covered in the analysis. To do this, we remove a year of data from both sides of the crisis and then make a simple mean adjustment, adding a constant for the post-1993 period to eliminate the discontinuity. In a way, the ERM crisis removal provides us with a rough picture of how GDP per capita figures of the sample countries would look like if the decline caused by the ERM crisis had not taken place. ${ }^{20}$

\footnotetext{
${ }^{18}$ We thank a referee for correctly pointing out that, besides the ERM crisis, other factors such as the completion of the Single Market in 1992 and the opening up of Eastern Europe to world markets had significant impacts on the process of overall European integration, causing a significant adjustment in trade flows among European economies, especially for Spain and Portugal.

${ }^{19}$ Simulations were run on mainly two different themes, the first one changing the break magnitude and the other changing the distance between the two breaks. Overall results show increased likelihood of irrelevant dates as: (1) breaks are indistinguishable from each other in magnitude and (2) these breaks get farther away from each other. More detail on these results can be provided by the authors upon request.

${ }^{20}$ The Vogelsang test is designed to measure a "simultaneous" mean and trend break independent of the serial correlation. Had things been any different after the ERM (i.e., if the countries moved to another steady state path), the Vogelsang test would place the break at the artificial one we generated.
} 
Table 2

Endogenous PSW break test of the deterministic trend of country GDP/capita (difference from the French Benchmark) (ERM removed)

\begin{tabular}{|c|c|c|c|c|c|c|}
\hline Countries & Pre-mean & Pre-trend & Post-mean & Post-trend & Estimated break date & Accession date \\
\hline Austria & $-0.166 * *$ & $0.004 * *$ & $0.023^{*}$ & 0.000 & 1996Q3 & 1995Q1 \\
\hline Finland & $-0.092 * *$ & $0.010^{* * *}$ & $0.499 * *$ & $0.004 *$ & 1994Q3 & 1995Q1 \\
\hline Portugal & $-1.508 * *$ & $-0.001 * *$ & $-1.342 * *$ & $0.007 * *$ & 1987Q4 & 1986Q1 \\
\hline Spain & $-0.749 * *$ & 0.000 & $-0.610^{* *}$ & $0.004 * *$ & 1987Q3 & 1986Q1 \\
\hline Sweden & $0.181 * *$ & $0.002 *$ & $0.361^{* *}$ & -0.001 & 1995Q3 & 1995Q1 \\
\hline
\end{tabular}

Notes: Reported estimates come from the estimation of Eq. (28) using the Vogelsang (2001) test on individual GDP per capita differences from France as mentioned below Table 1. Hence, negative numbers indicate coefficients below those of France. The only difference between the two tables comes from the removal of 1 year windows from each side of the of the ERM crisis in 1992. Estimated break date reports the endogenously attained date while the last column shows the accession date of each country.

Our contention is that, if this method were inappropriate, we would bear the costs of data removal and mean adjustment by endogenously finding the new break around our artificially generated one. The findings show that this is not the case.

Table 2 illustrates the results with two years removed from data around the ERM crisis. The second and fourth columns of both tables display pre- and post-break mean difference from that of the benchmark of log GDP per capita, namely $\mu_{1}$ and $\mu_{2}$ of Eq. (28), respectively; the third and the fifth columns show the pre- and post-break parameter estimates for the productivity growth, $\delta_{1}$ and $\delta_{2}$, respectively; and the last columns report the endogenously estimated break date along with the actual membership dates. To better understand how to interpret these results, consider Austria. This country exhibits a lower quarterly mean GDP per capita compared to France (in log terms) and about $0.4 \%$ higher productivity growth than France prior to accession. After 1995, the two counties' productivity growth is equalized, and Austria's GDP per capita marginally exceeds that of France. The results indicate that our methodology, though unconventional, is able to highlight some interesting patterns about the break dates and productivity growth rates.

Note that in Table 2 the endogenously determined break dates are strikingly close to each country's accession date. Next, observe that the initial GDP per capita levels of every country, except Sweden, lag behind that of France. This trend changes after 1995 with all the three latecomers having higher mean GDP per capita levels than does France. It is noteworthy that the countries that joined the EU early benefit from strong productivity increases while the others do worse when compared to France. ${ }^{21}$ This finding is puzzling and requires further scrutiny because our model suggests that integration should lead to the sharing of innovations and hence productivity growth in all of the member countries.

\footnotetext{
${ }^{21}$ The significant productivity growth rates are not only different from 0 , but they are also different from one another between the two periods. We conducted a Monte Carlo simulation to evaluate how one regime differs from another. With a sample size of 100 and structural change coefficient values close to the estimates in Table 2, we apply Vogelsang's method to 2000 generated series. While not a formal test with analytic properties, the outcome of the simulation exercise is in line with the theory developed in this paper and supports our claim that membership generates a change in the mean (steady state) and trend (technological growth rate) parameters. Detailed results are available from the authors upon request.
} 


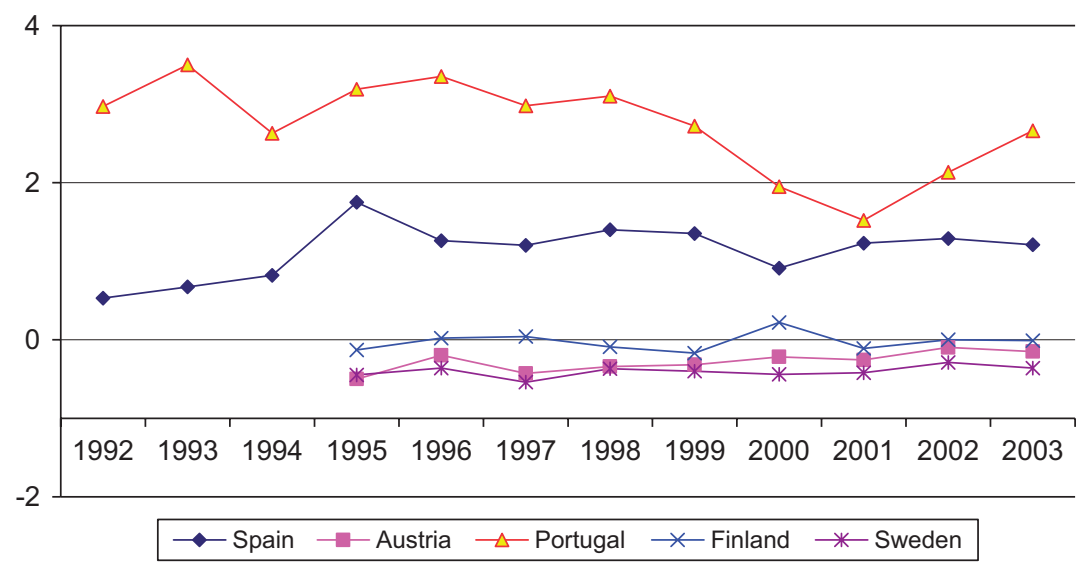

Fig. 1. Net operational transfers after membership (\% of GDP).

In our structural break tests, this seems to be true only for the countries that joined early, so we try to identify other differences that could have led to this growth disparity.

It is interesting to observe that other members' GDP per capita, in comparison to that of France, changes according to the time of accession; in particular, a decline in the relative productivity occurs after 1995 in those countries with a GDP per capita level close to that of France. This observation might explain why some relatively wealthier countries tend to hesitate to join the EU. The institutional arrangements of the EU, namely the Structural and Cohesion Funds or net budget transfers that these countries receive or contribute depending on their need for income equalization may play an important role in this decision to join or not. As shown in Fig. 1, the countries that display higher productivity growth levels compared to France were net recipients of EU operational funds, whereas the ones who experienced losses in their comparative productivity were net contributors. ${ }^{22}$ Upon closer examination, the transfer levels closely correspond to the productivity performance of each joining member. ${ }^{23}$ For instance, Portugal and Spain have increases in their productivity and the large inflows of operational funds, while Sweden and Finland, who experienced declines in their productivity down to French levels, were net givers. Austria, being a net giver one year and net recipient in the next, experienced a decline in its productivity but maintained a level above that of France. In short, these result suggest one of the following: Either there is a productivity effect of Structural and Cohesion Funds not included in the theory section or all sample countries are moving gradually from one steady state to another, causing $f_{i}$ to affect not only the steady state levels as in Eq. (23) but also the growth rate to these new

\footnotetext{
${ }^{22}$ The flows of structural funds in actuality are higher than the net operational transfers values used in this study, as the latter constitutes only a small of part of the EU budget. The comparison of individual country performances to the EU benchmark and lack of long-run time series data on Structural and Cohesion Funds dictated our choice of using net operational transfers. In addition, using much larger Cohesion Fund inflows would only strengthen our results.

${ }^{23}$ The cross-sectional correlation between the productivity growth changes and the average net operational transfers is 0.95 .
} 
levels. $^{24}$ If the former is true, then our initial results have two important policy implications: (1) Structural operations of the EU are effective and serving their purpose in increasing the steady state levels, but (2) they are also costly in the short run in terms of a lower growth rate among the net contributors. However, considering the eventual decline in transfers as the members of the EU converge and the productivity benefits of being a member of a more prosperous union, the temporary growth costs of the transition period to the wealthier countries should not be substantial.

\subsection{Decomposition of productivity using the Malmquist indexes}

The above results and the conclusions we draw from them are consistent with the theory in LPS (1997) only under the critical assumption that the sample countries are continuously in their steady states. However, as seen from the section above, examining growth rates does not provide a clear picture of (i) the changes in the steady state and (ii) how fast the transition from on steady state to another occurs. We also need to be sure that the breaks in the mean and the growth rate in GDP per capita are not the results of the inflow (outflow) of capital into (from) the new members after their accession, and that the trend coefficient truly represents the productivity growth rate. Hence, we supplement our earlier results with a data envelopment approach that takes into account the short run deviations from the steady states. Consequently, we further probe the changes in productivity with the use of Malmquist indexes prior to moving on to the analysis of convergence rate.

Because the factor shares of our sample countries are similar, ${ }^{25}$ the production functions of the sample countries and of the benchmark can be grouped in the following simplified form

$$
\frac{Y_{i t} / \theta_{i t}}{Y_{F t} / \theta_{F t}}=\frac{A_{i t} Z_{i t}}{A_{F t}}\left(\frac{x_{i t}}{x_{F t}}\right)^{\alpha},
$$

where $\theta$ is again the inefficiency parameter, $A$ and $Z$ represent productivity measures, $x$ is, without loss of generality, the composite input $(K$ and $L), \alpha$ is the common factor share, and subscripts $i$ and $F$ represent country $i$ and France, respectively. Assuming that the exogenous productivity growths of sample countries are the same as that of France, ${ }^{26}$ i.e., $A_{i t} \cong A_{F t}$,

$$
\ln \left(Y_{i t}\right)-\ln \left(Y_{F t}\right)=\left[\ln \left(Z_{i t}\right)\right]+\left[\ln \left(x_{i t}\right)-\ln \left(x_{F t}\right)\right]+\left[\ln \left(\theta_{i t}\right)-\ln \left(\theta_{F t}\right)\right],
$$

where the term in the first brackets on the right hand side shows the relative "technological change" purely due to integration, the middle term is the input differences, and the last bracketed term represents the relative "efficiency change". These relative performances are

\footnotetext{
${ }^{24}$ To be more precise, due to the change in the steady state in Eq. (23) (the terms with $\zeta$ and $f$ ), the steady state level of capital will increase at the rate of $\dot{k} / k=(s+f) k^{1-\alpha}-(g+n+\zeta+\delta)$, causing the output per capita to increase at $\dot{y} / y=\alpha(s+f) k^{1-\alpha}-\alpha(g+n+\zeta+\delta)+(g+\zeta)$. These equations show that the speed of growth in the transition phase will be affected by the difference between the steady state levels and the foreign capital inflow (hence the cross sectional correlation). Estimating a trend function even in the case of a nonlinear transition period should not pose a big problem for our estimation since the new estimated trend change will be more conservative than the actual trend change.

${ }^{25}$ See Bernanke and Gurkaynak (2001).

${ }^{26}$ Note that France received the integration benefit, $Z$, having joined the Union earlier.
} 


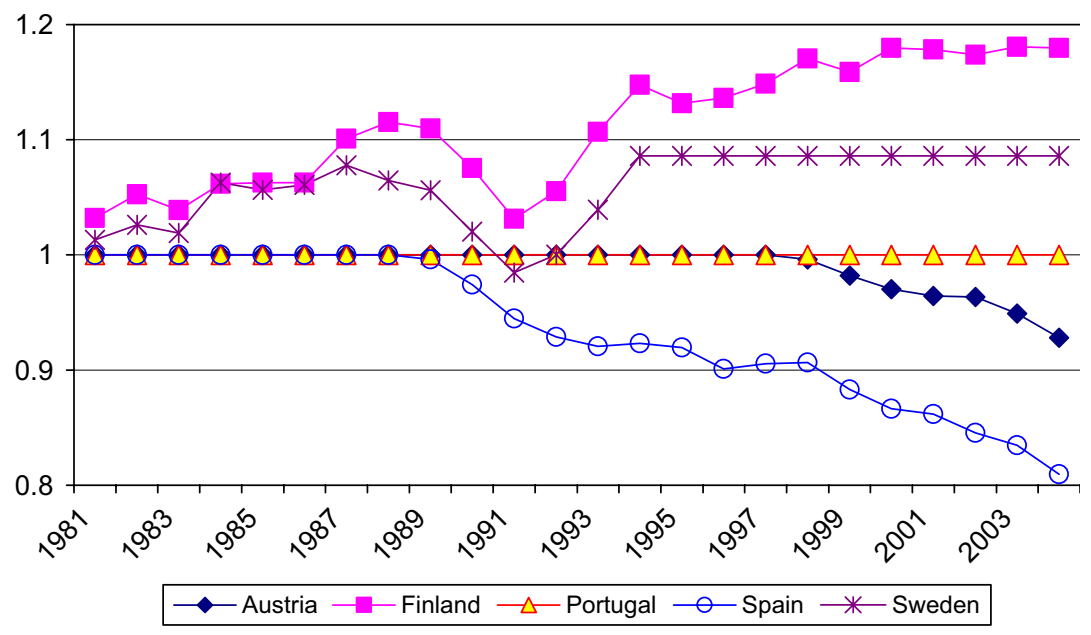

Fig. 2. Relative cumulative efficiency change index.

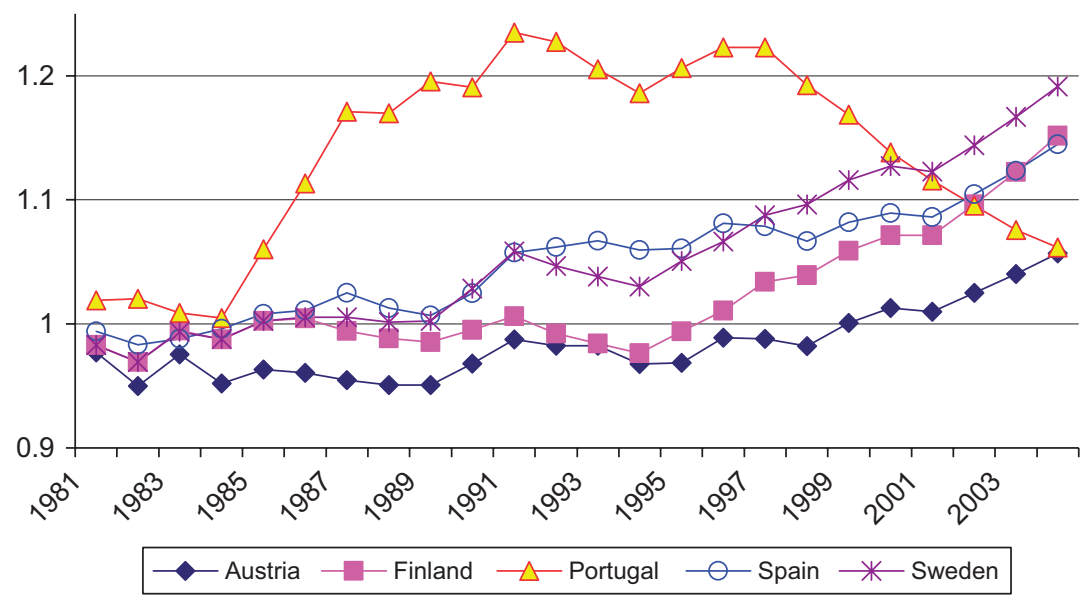

Fig. 3. Relative cumulative technological change index.

shown in Figs. 2 and 3. ${ }^{27}$ These Figures report cumulative index values, which are obtained by sequential multiplication of the year-to-year values of each index. The results show that (i) relative efficiency worsens for early joiners, namely, Spain and Portugal, which is likely due to their fast paced capital accumulation and declining unemployment, indicating their inability to absorb these inputs at the same pace (see Denis et al., 2002, who find Spain's NAIRU decreasing from around $20 \%$ down to $11 \%$ and Portugal's from over $8 \%$ to under 5\%; also see Fig. 4 for their output per capita), (ii) Sweden and Finland show improvement in relative efficiency, mostly related to the ERM recovery (Fig. 4 confirms the efficiency findings in (i) and (ii)), (iii) all countries display higher rates of technological change than France, especially after their membership, (iv) the technological change rate of

\footnotetext{
${ }^{27}$ Tabular values for all the graphs are available from the authors upon request.
} 


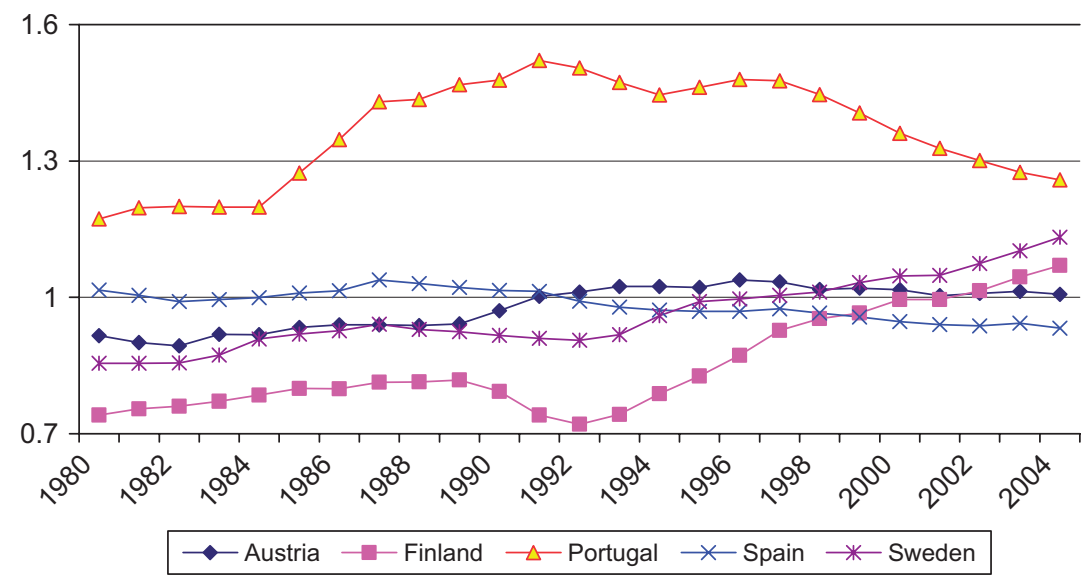

Fig. 4. Output to capital ratio (France comparison).

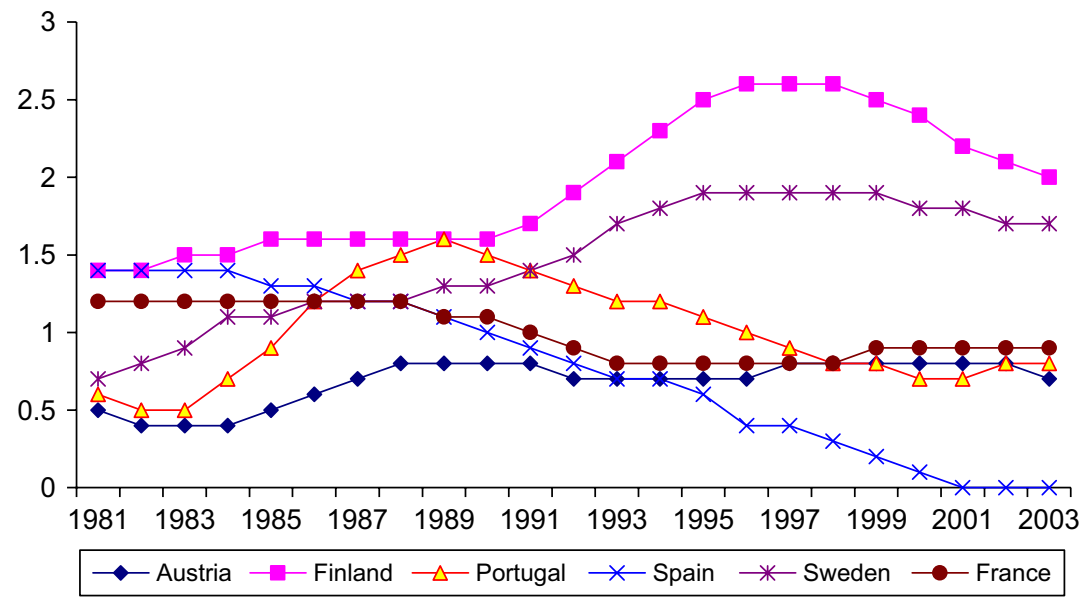

Fig. 5. TFP contribution to growth in \% (Denis et al., 2002).

early joiners slows down in the second half of the 1990s, while the late joiners' improvement picks up with their membership; ${ }^{28}$ and (v) the decomposed results are different from those obtained from plain growth accounting of TFP because they can determine the source of improvements. Fig. 5 displays a calculation of TFP's contribution to potential output growth by Denis et al., 2002, which does not allow for inefficiency or temporary deviations from the steady state. ${ }^{29}$ Since their TFP is effectively the product of our two $M$-indexes, the picture one gets of the productivity impact of integration is quite

\footnotetext{
${ }^{28} \mathrm{We}$ should also note that the R\&D expenditure as a percentage of GDP of late-joiners (not reported here) increase significantly in the late 1990s.

${ }^{29}$ They calculate TFP contribution using potential output. Another calculation that uses actual output and finds similar results is not reported for the sake of brevity.
} 
Table 3

Bai-Perron structural break test results in the autoregressive $(1-\lambda=$ convergence) coefficient (difference from the French Benchmark) (ERM removed)

\begin{tabular}{lcclllll}
\hline Country & UDMAX & WDMAX & $\begin{array}{l}\text { Sequential } \\
(2 \mid 1)\end{array}$ & $\begin{array}{l}\text { Sequential } \\
(3 \mid 2)\end{array}$ & BIC choice & $\begin{array}{l}\text { Break dates } \\
\text { at } 5 \%\end{array}$ & $1-\lambda$ \\
\hline Austria & 2.25 & 2.35 & 0.85 & 0.86 & 0 & & 0.41 \\
Finland & $\mathbf{1 4 . 4 1 * *}$ & $\mathbf{1 4 . 4 1 * *}$ & 4.78 & 4.78 & 1 & $1993 \mathrm{Q} 1$ & $0.82-0.26$ \\
Portugal & 5.97 & 7.52 & 7.70 & 1.83 & 0 & 0.31 \\
Spain & $\mathbf{1 1 . 2 4 * *}$ & $\mathbf{1 6 . 2 3} * *$ & 1.53 & 1.36 & 1 & $1985 \mathrm{Q} 3$ & $0.09-0.73$ \\
Sweden & $\mathbf{7 . 9 9 *}$ & $\mathbf{1 4 . 5 0 * *}$ & 7.40 & $2.12^{*}$ & 0 & $(1995 \mathrm{Q} 1)$ & $0.31($ to \\
& & & & & & & $0.37)$ \\
\hline
\end{tabular}

Notes: Reported results come from the Bai-Perron multiple structural break test using the specification $y_{t}^{*}=$ $\phi+\lambda_{t} y_{t-1}^{*}+u_{t}$ for the dependent variables, which are detrended GDP/capita deviations from France. A maximum of three breaks are allowed in $\lambda$. UDMAX and WDMAX tests report double maximum tests, which have the null of no-break versus the alternative of at least one. Sequential tests examine the null of $r$ breaks versus $r-1 . * *(*)$ indicates $95 \%(90 \%)$ significance levels. The results are reported in parentheses when the number of breaks has not been confirmed by the BIC. The last column reports $1-\lambda$ rather than the autoregressive coefficient. The above tests have been run with AR(1) specification. Changing the lag specifications to higher orders do not lead to any significant changes other than no-rejection result in Sweden in the double maximum tests, indicating lack of any breaks.

different. We observe that Spain and Portugal benefited early on from TFP growth, but in the second half of 1990s, countries like Finland and Sweden showed superior TFP performance. This conflict in results is important because it shows that a failure to account for inefficiency in production could lead to the misperception that productivity falls in countries like Spain. However, what seems to be a decline in the productivity is instead a significant shifting out of their frontier at a rate faster than that of France combined with even a larger imbalance in their factor markets. In short, our theoretical claim of integration leading to improvement in productivity is confirmed. Spain and Portugal experienced a reduction in their efficiency, likely due to the inability to efficiently utilize the large capital inflows and the wage-increasing effect of structural operations geared to reduce unemployment in the early years of their EU membership. Nonetheless, all countries showed strong productivity growth after their accession due to the increase in the rate of technological improvement.

\subsection{Convergence rates}

In the final section of our analysis, we estimate the convergence rates by using the BP (1998) method, allowing for a maximum of three breaks in the convergence rate. The results, reported in Table 3, show that only two countries, Spain and Finland, seem to have a change in the convergence rate. Spain's convergence has increased strongly after its accession date, as suggested by theory. Finland experienced a decline in the convergence rate; however, we believe that this finding is mainly due to the removal of the ERM because the endogenous break date is close to the artificial one we created. The other countries in the sample do not display noticeable changes in their convergence levels, except for weak evidence of an increase in Sweden. ${ }^{30}$ The lack of convergence is not

\footnotetext{
${ }^{30}$ There is weak evidence of a break for Sweden during its accession date, but it disappears at higher autoregression specifications.
} 
consistent with the expectations of the theory set out in Eq. (13). However, there are two possible reasons for these findings: A change in the serial correlation of technology process in Eq. (6) and the serial correlation generated by the linear trend estimation in the nonlinear transition phase. We rely on LPS's empirical finding of no change in the serial correlation of technology and focus on the latter possibility. Despite the assumption in Solow's growth theory of constant factor shares, it is not quite clear how the factor shares would be determined during a transition period from one steady state to another. Allowing for time varying factor shares during the transition produces a possible explanation to our empirical results. Using the labor share of value added data from OECD STAN Indicators database $^{31}$ we observe that the countries in which we fail to find a convergence rate break, Austria and Portugal, have opposing short-run movements in the technology parameter, $\zeta$, and the labor share, $(1-\alpha)$. Since the convergence rate is the product of these two parameters, their opposite movements offset the effect of integration on the convergence rate. When they move in the same direction, as in Spain, the outcome is the drastic shortrun increase in Spain's convergence rate. This explanation is only valid during transition from one steady state to another, and the factor shares will again become constant in the steady state. Thus, we only display the short-run fluctuations in these parameters in Figs. $6 a-c^{32}$ and leave further analysis of how transition process affects short run fluctuations in factor shares for future research. We conclude our discussion with a final observation about the level of convergence rates. Our convergence rate estimates are higher than the 0.24 mean estimate of LPS (1997) for the OECD countries, but the statistical difference of these differences is not investigated.

\subsection{Summary of the findings}

In conclusion, we find evidence supporting most of the testable implications of our theoretical model. The steady state levels of income, productivity growth rates, and some members' convergence rates increase with integration into the EU. We believe that the mixed results regarding productivity changes are likely due to the transition from one steady state to another after accession (see footnote 24). Therefore, the large increase in these economies' trend growth, as suggested by the structural break tests results, is likely affected by the inflow of capital in the form of Structural and Cohesion Funds. Nonetheless, our Malmquist technological change index indicates that productivity increases for both donor and recipient countries, supporting our expectation of knowledge and technology diffusion. We observe the same phenomenon in the three later joining countries, though more so in Finland and Sweden than in Austria. Despite showing significant productivity increases after their accession, the savings outflow might have temporarily constrained these countries' growth rates during the transition period. In short, our empirical evidence suggests the importance of productivity spillovers and knowledge sharing in the Union, but it also indicates that other important aspects of integration associated with its institutional operations, such as the net budget transfers, including Structural and Cohesion Funds, can also have a significant short-run impact on how fast countries converge to the Union standards.

\footnotetext{
${ }^{31}$ http://oberon.sourceoecd.org

${ }^{32}$ The reported labor shares are relative to France.
} 
a

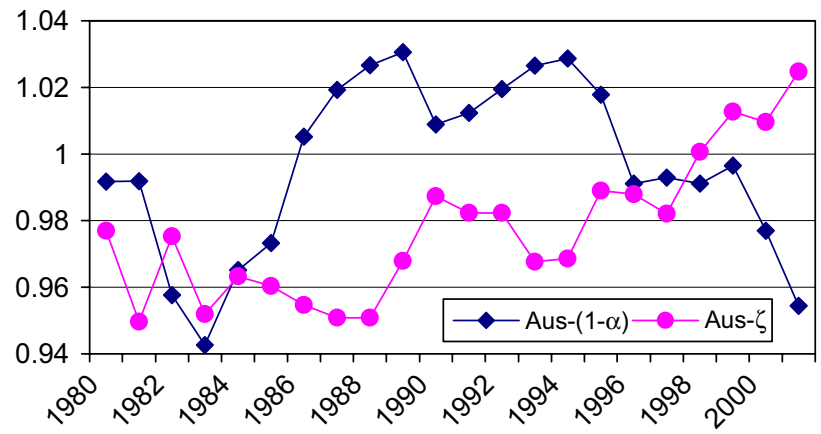

b
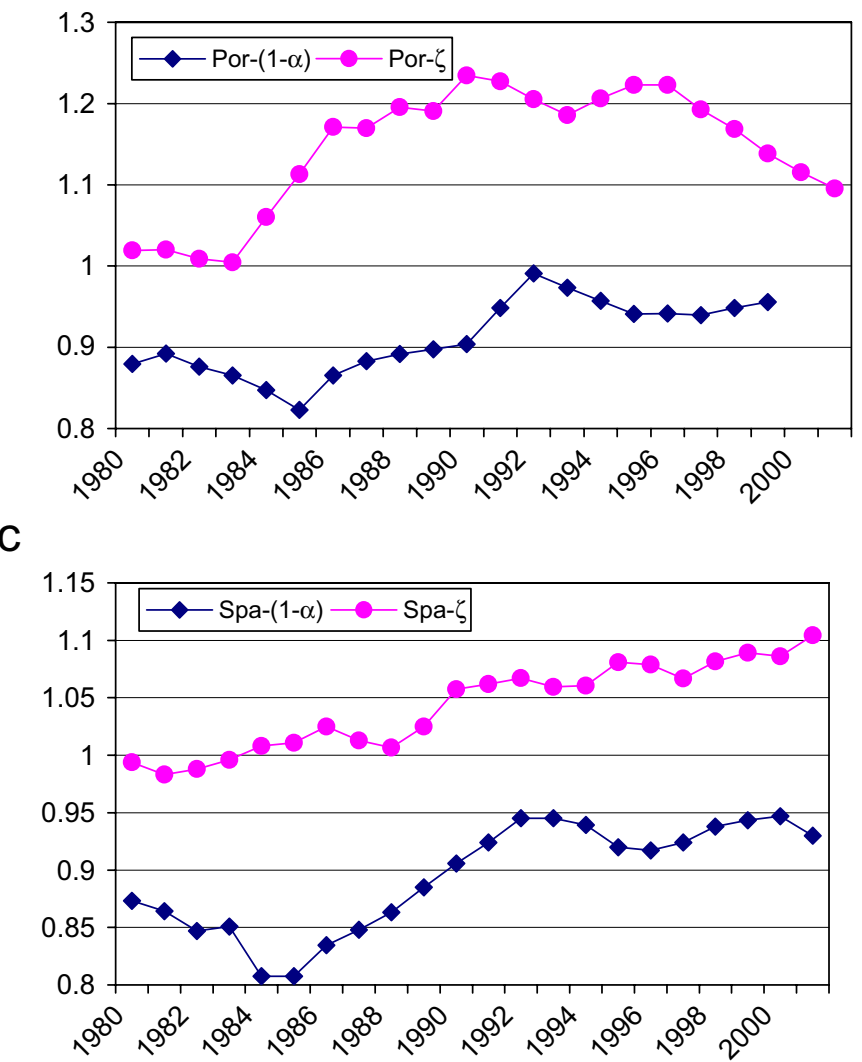

Fig. 6. (a) Austria's technological change rate and labor share, (b) Portugal convergence rate and labor; share, and (c) Spain convergence rate and labor share.

\section{Conclusion and policy implications}

In this study, we use a new methodology to estimate the impact of European integration on convergence and productivity growth, one that does not require the use of proxy 
variables. Our theoretical formulation captures the unobservable process of knowledge sharing resulting from integration and its effect on growth, productivity, and convergence rate after accession. Using a series of structural break tests and data envelopment analysis, we test the theoretical predictions of the model for the five recent members to the EU15. The results show improved rates of productivity growth after accession over and above the EU benchmark level. In addition, we observe an increased pace of overall growth due to capital accumulation as a result of Structural and Cohesion Funds.

Our key implication for policy is that our results show that integration enhances productivity and growth. The institutional aspects of EU integration, such as Structural and Cohesion Funds, play an effective role in furthering economic growth. Providing such funds for new member states, despite temporary distortions in the pricing of productive factors in the short run, helps the recipient economies in the long run by allowing them to catch up faster with the core EU15 members.

\section{Acknowledgement}

We thank two anonymous referees, the Editor (T. Gylfason), N. Arnwine, J. Brada, J. Crespo-Cuaresma, K. Drakos, B. Egert, A. Y. Evrensel, R. Gurkaynak, S. KalemliOzcan, L. T. Orlowski, C. Saglam, S. Sayek, S. Stefanou, E. Yeldan, and the participants of the 7th International Economic Research Center Conference and of the 49th East Jour Fixe for their valuable comments on the earlier versions of this paper. The usual disclaimer applies.

\section{Appendix A. Structural break tests and the calculation of the Malmquist index}

\section{A.1. Vogelsang $(1998,2001)$ test}

Vogelsang considers the specification ${ }^{33}$

$$
y_{t}=X_{y t} \beta+u_{t},
$$

where $X_{y t}$ is $[1, t]$. For more than one coefficient restriction, one of the tests can be summarized as

$$
P S W_{T}=\frac{T^{-1}(R \hat{\beta}-r)^{\prime}\left[R\left(X_{y}^{\prime} X_{y}\right)^{-1} R^{\prime}\right]^{-1}(R \hat{\beta}-r)}{\left(100 T^{-1} s_{z}^{2} \exp \left(b J_{T}(m)\right)\right)},
$$

where $R$ and $r$ represents the restriction matrix and vector, respectively, and $J_{T}$ is the Park and Choi (1988) unit root test statistic obtained from the following regression

$$
\begin{aligned}
& y_{t}=X_{y t} \beta+\sum_{i=2}^{m} c_{i} t^{i}+u_{t}, \\
& J_{T}(m)=\left(R S S_{y}-R S S_{J}\right) / R S S_{J} .
\end{aligned}
$$

$J_{T}$ is the Wald statistic that tests the joint hypothesis of $c_{2}=c_{3}=\cdots=c_{m}=0$. In short, Vogelsang's test corrects for the potential incorrect inference, mainly due to the possibility

\footnotetext{
${ }^{33}$ For details and other specifications like PS and TW statistics please refer to Vogelsang (1998).
} 
of a unit root, by scaling down the statistics with a value that would increase in size in the case of nonstationarity.

Spanning the standard set of breaks introduced by Perron (1989), namely the mean, trend, and the mean and trend, Vogelsang (2001) derives the asymptotics in cases of both known and unknown break dates. ${ }^{34}$ We favor not imposing a break date in our estimations since finding the break dates endogenously at the times of accession would be a direct test of our theory. In the endogenous break tests, initially the break date is estimated by maximizing a Wald statistic for each possible $T_{b} \in \Lambda$ where $\Lambda$ is the sample trimmed from both ends. Then, using the estimated break date, normalized $t$-statistics are obtained using the altered version of Eq. (A.1) as follows:

$$
y_{t}=\mu_{1} D U_{1 t}+\mu_{2} D U_{2 t}+\delta_{1} D T_{1 t}+\delta_{2} D T_{2 t}+u_{t},
$$

where $D U_{1 t}=1$ if $t \leqslant T_{b}$ (the break date) and zero otherwise, $D U_{2 t}=1$ if $t>T_{b}$ and zero otherwise, $D T_{1 t}=t$ if $t \leqslant T_{b}$ and zero otherwise, and finally $D T_{2 t}=t-T_{b}$ if $t>T_{b}$ and zero otherwise. His analysis, using Maddison's data (Maddison, 1991), and a later application by Tomljanovich and Vogelsang $(2002)^{35}$ that focuses mainly on convergence issues, provide interesting exploitations of this methodology.

\section{A.2. Bai and Perron (1998) test}

The general form of the Bai-Perron methodology considers the following multiple structural break model, with $m$ breaks ( $m+1$ regimes)

$$
y_{t}=x_{t}^{\prime} \beta+z_{t}^{\prime} \delta_{j}+u_{t}
$$

for $t=T_{j-1}+1, \ldots, T_{j}$ and $j=1, \ldots, m+1 . y_{t}$ is the observed dependent variable at time $t ; x_{t}(p \times 1)$ and $z_{t}(q \times 1)$ are the vector of covariates, $\beta$ and $\delta_{j}$ are the corresponding vectors of coefficients, and $u_{t}$ is the disturbance term at time $t$. The break points $(T)$ are treated as unknown, and are estimated together with the unknown coefficients when $T$ observations are available. In the terminology of BP, this is a partial structural change model, in the sense that $\beta$ does not change, and is effectively estimated over the entire sample. If $p=0$, this becomes a pure structural change model where all coefficients are subject to change. The recommended procedure for detecting structural breaks, suggested by BP, is the following. First, calculate the UDMAX and WDMAX statistics. ${ }^{36}$ These are double maximum tests, where the null hypothesis of no structural breaks is tested against the alternative of an unknown number of breaks. These tests are used to determine if at least one structural break is present. In addition, the $\operatorname{SupF}(0 \mid l)$ is a series of Wald tests for the hypothesis of 0 breaks vs. $l$ breaks. In this paper, the maximum number of breaks $(l)$ is chosen to be 3 . If these tests show evidence of at least one structural break, then the number of breaks can be determined by the sequential statistic, $\operatorname{SupF}(l+1 \mid l)$. If this test is significant at the $5 \%$ level, then $l+1$ breaks are chosen. Finally, we choose the number of breaks by the Bayesian Information Criteria (BIC).

\footnotetext{
${ }^{34}$ Interestingly, one of the supremum statistics he suggests performs better than some popular statistics in identifying shifts in slope.

${ }^{35} \mathrm{We}$ are grateful to the authors for providing us with the Gauss routine used in this paper.

${ }^{36}$ UDMAX stands for equally weighted double maximum test while WDMAX refers to the weighted version.
} 


\section{A.3. Färe et al. (1994): Malmquist index}

Using the notation in Färe et al. (1994), a production technology $S_{t}\left\{x_{t}, y_{t}\right\}$ maps inputs $x_{t}$ into outputs $y_{t}$, producing the distance functions

$$
D_{\mathrm{o}}^{t}\left(x_{t}, y_{t}\right)=\left(\sup \left\{\theta:\left(x_{t}, \theta y_{t}\right) \in S_{t}\right\}\right)^{-1}
$$

that "... seek the reciprocal of the greatest proportional increase in outputs, given inputs, such that output is feasible" (Färe et al., 1994, p. 69). In this setup, subscript 'o' stands for output and $\theta$ could be described as the inefficiency parameter, measuring how far the production is from the frontier. Using the distance functions from consecutive time periods, one can obtain the Malmquist index

$$
M_{\mathrm{o}}\left(y_{t+1}, x_{t+1}, y_{t}, x_{t}\right)=\frac{D_{\mathrm{o}}^{t+1}\left(x_{t+1}, y_{t+1}\right)}{D_{\mathrm{o}}^{t}\left(x_{t}, y_{t}\right)} \times\left[\left(\frac{D_{\mathrm{o}}^{t}\left(x_{t+1}, y_{t+1}\right)}{D_{\mathrm{o}}^{t+1}\left(x_{t+1}, y_{t+1}\right)}\right)\left(\frac{D_{\mathrm{o}}^{t}\left(x_{t}, y_{t}\right)}{D_{\mathrm{o}}^{t+1}\left(x_{t}, y_{t}\right)}\right)\right]^{1 / 2},
$$

where the first term measures the technological change (or the shift in the production frontier) and the geometric mean of the ratios inside the brackets measure the change in efficiency (or how much the distance to the frontier changes). Improvements in both parts of the index are shown by values greater than unity. For the Cobb-Douglas production function $y_{t}=A(t) \Pi_{n=1}^{N}\left(x_{t}^{n}\right)^{\alpha_{n}}$ the distance function becomes

$$
D_{\mathrm{o}}^{t}\left(x_{t}, y_{t}\right)=y_{t} /\left(A(t) \prod_{n=1}^{N}\left(x_{t}^{n}\right)^{\alpha_{n}}\right)
$$

leading to the Malmquist index becoming the ratio of the efficiency parameters

$$
M_{\mathrm{o}}\left(y_{t+1}, x_{t+1}, y_{t}, x_{t}\right)=A(t+1) / A(t) .
$$

\section{References}

Alfaro, L., Chanda, A., Kalemli-Ozcan, S., Sayek, S., 2004. FDI and economic growth: the role of local financial markets. Journal of International Economics 64 (1), 89-112.

Bai, J., Perron, P., 1998. Estimating and testing linear models with multiple structural changes. Econometrica 66, 47-78.

Baldwin, R.E., 2000. Trade and growth: still disagreement about the relationships. OECD Economics Department, Working Papers, no. 264.

Baldwin, R.E., Seghezza, E., 1996. Testing for trade-induced investment-led growth. NBER Working Paper Series, no. 5416.

Barrell, R., Pain, N., 1997. Foreign direct investment, technological change and economic growth within Europe. Economic Journal 107, 1770-1786.

Barrell, R., Pain, N., 1999. Domestic institutions, agglomerations and foreign direct investment in Europe. European Economic Review 43, 925-934.

Bernanke, B., Gurkaynak, R., 2001. Is growth exogenous? In: Taking Mankiw, Romer and Weil seriously." NBER Macroeconomics Annual 2001, pp. 11-57.

Beugelsdijk, M., Eijffinger, S.C.W., 2003. The effectiveness of structural policy in the European Union: an empirical analysis for the EU-15 during the period 1995-2201. CEPR Discussion Paper, no. 3879, London.

Boldrin, M., Canova, F., 2003. Regional policies and EU enlargement. CEPR Discussion Paper No. 3744.

Borensztein, E., De Gregorio, J., Lee, J.W., 1998. How does foreign direct investment affect economic growth? Journal of International Economics 45, 115-135. 
Carkovic, M., Levine, R.E., 2002. Does foreign direct investment accelerate economic growth? University of Minnesota, Department of Finance, Working Paper.

Caves, D.W., Christensen, L.R., Diewert, W.E., 1982. The economic theory of index numbers and the measurement of input, output, and productivity. Econometrica 50 (6), 1393-1414.

Coe, D.T., Helpman, E., 1995. International R \& D spillovers. European Economic Review 39, 859-887.

Crespo-Cuaresma, J., Ritzberger-Grünwald, D., Silgoner, M.A., 2002. Growth, convergence and EU membership. National Bank of Austria, Working Paper no. 62.

Denis, C., Kieran, M.M., Werner, R., 2002. Production function approach to calculating potential growth and output gaps - estimates for the EU member States and the US. DG ECFIN Economic Paper no. 176, Brussels.

Dohrn, R., Milton, A.R., Radmacher-Nottelmann, N.A., 2001. The impact of trade and FDI on cohesion. Final Report to the European Commission DG Regional Policy, RWI Essen.

Durham, J.B., 2004. Absorptive capacity and the effects of foreign direct investment and equity foreign portfolio investment on economic growth. European Economic Review 48 (2), 285-306.

Ederveen, S., Gorter, J., 2002. Does European cohesion policy reduce regional disparities? CPB Discussion Paper No 15.

Ederveen, S., Gorter, J., de Mooij, R., Nahais, R., 2002. Funds and games: The economics of European cohesion policy. CPB Netherlands Bureau for Economic Analysis, Den Haag.

Engelbrecht, H., 1997. International R \& D spillovers, human capital and productivity in OECD economies: an empirical investigation. European Economic Review 41, 1479-1488.

European Commission, 2001. Unity, solidarity diversity for Europe, its people and territory. Second Paper on Economic and Social Cohesion. Office for Official Publications of the European Communities, Luxembourg.

Färe, R., Grosskopf, S., Norris, M., Zhang, Z., 1994. Productivity growth, technical progress, and efficiency change in industrialized countries. American Economic Review 84 (1), 66-83.

Fayolle, J., Lecuyer, A., 2000. Regional growth, national membership and European structural funds: an empirical appraisal. OFCE Working Paper No. 00-02, Paris.

Frankel, J.A., Romer, D., 1999. Does trade cause growth?”. American Economic Review 89 (3), 379-399.

Gao, T., 2005. Foreign direct investment and growth under economic integration. Journal of International Economics 67, 157-174.

Greenwood, J., Hercowitz, Z., Krusell, P., 1997. Long-run implications of investment-specific technological change. American Economic Review 87 (3), 342-362.

Griffith, R., Redding, S., Reenen, J.V., 2004. Mapping the two faces of R \& D: productivity growth in a panel of OECD industries. Review of Economics and Statistics 86 (4), 883-895.

Grossman, G.M., Helpman, E., 1991. Innovation and growth in the global economy. MIT Press, Cambridge, MA.

Henrekson, M., Thorstensson, J., Thorstensson, R., 1997. Growth effects of European integration. European Economic Review 41, 1537-1557.

Hercowitz, Z., 1998. The 'Embodiment' controversy: a review essay. Journal of Monetary Economics 4 (1), $217-224$.

Kao, C., Chiang, M., Chen, B., 1999. International R\&D spillovers: an application of estimation and inference in panel cointegration. Oxford Bulletin of Economics and Statistics 61 (0), 691-709.

Krussel, P., 1998. Investment specific R\&D and the decline in the relative price of capital. Journal of Economic Growth 3 (2), 131-141.

Lee, K., Pesaran, M.H., Smith, R., 1997. Growth and convergence in multi-country empirical stochastic Solow model. Journal of Applied Econometrics 12 (4), 357-392.

Maddison, A., 1991. Dynamic Forces in Capitalist Development. Oxford University Press, Oxford.

Martin, C., Velázquez, F.J., 2001. An assessment of real convergence of less developed EU members: Lessons for the CEEC candidates. Working Paper No. 5/2001, European Economy Group.

Park, J.Y., Choi, B., 1988. A new approach to testing for a unit root. Working Paper \#88-23, Department of Economics, Cornell University.

Perron, P., 1989. The great crash, the oil price shock, and the unit root hypothesis. Econometrica 57, 1361-1401.

Rivera-Batiz, R.A., Romer, P.M., 1991. Economic integration and growth. Quarterly Journal of Economics 56, $531-555$.

Saggi, K., 2000. Trade, foreign direct investment, and international technology transfer: a survey. The World Bank Research Observer 17 (2), 191-235.

Solanes, J.G., Ramon, M.D., 2002. The impact of European structural funds on economic convergence in European countries and regions. In: Meeusen, W., Vilaverde Castro, J. (Eds.), Convergence Issues in the European Union. Edward Publishing Ltd, pp. 61-82. 
Tomljanovich, M., Vogelsang, T.J., 2002. Are US regional incomes converging? Using new econometric methods to examine old issues. Empirical Economics 27, 49-62.

Vogelsang, T.J., 1998. Trend function hypothesis testing in the presence of serial correlation. Econometrica 66, $123-148$.

Vogelsang, T.J., 2001. Testing for a shift in trend when serial correlation is of unknown form. Cornell Department of Economics mimeo.

Yanikkaya, H., 2003. Trade openness and economic growth: a cross-country empirical investigation. Journal of Development Economics 72, 57-89.

Wagner, M., Hlouskova, J., 2002. The CEEC10's real convergence prospects. CEPR Discussion Paper No. 3318.

Walde, K., Wood, C., 2004. The empirics of trade and growth: where are the policy recommendations? European Commission Economic Papers, No. 204. 